\title{
Measurements of Elastic Modulus and Fracture Toughness of an Air Plasma Sprayed Thermal Barrier Coating Using Micro-Cantilever Bending
}

\author{
Document Version \\ Submitted manuscript
}

Link to publication record in Manchester Research Explorer

Citation for published version (APA):

Chen, Y., Zhang, X., Zhao, X., Markocsan, N., Nylén, P., \& Xiao, P. (2019). Measurements of Elastic Modulus and Fracture Toughness of an Air Plasma Sprayed Thermal Barrier Coating Using Micro-Cantilever Bending. Surface \& Coatings Technology, 374, 12-20. https://www.sciencedirect.com/science/article/pii/S0257897219305109

Published in:

Surface \& Coatings Technology

\section{Citing this paper}

Please note that where the full-text provided on Manchester Research Explorer is the Author Accepted Manuscript or Proof version this may differ from the final Published version. If citing, it is advised that you check and use the publisher's definitive version.

\section{General rights}

Copyright and moral rights for the publications made accessible in the Research Explorer are retained by the authors and/or other copyright owners and it is a condition of accessing publications that users recognise and abide by the legal requirements associated with these rights.

\section{Takedown policy}

If you believe that this document breaches copyright please refer to the University of Manchester's Takedown Procedures [http://man.ac.uk/04Y6Bo] or contact uml.scholarlycommunications@manchester.ac.uk providing relevant details, so we can investigate your claim.

\section{OPEN ACCESS}


School of Materials

University of Manchester

Manchester

M13 9PL

Tel: 44-161 3065941

Fax: 44-161306 3586

Email: ping.xiao@manchester.ac.uk

Dear Prof. Joerg Patscheider,

Thanks for your efforts to arrange the second review of the manuscript entitled "Measurements of Elastic Modulus and Fracture Toughness of an Air Plasma Sprayed Thermal Barrier Coating Using Micro-Cantilever Bending" with the manuscript ID SURFCOAT-D-18-04033R1. We appreciate the extra comments given by Reviewer \#2. In this version, we have addressed all the comments (please see the "responses to reviewers" letter for details) and revisions have been made and highlighted accordingly in the text. I wish that the revisions are satisfactory for publication of the manuscript. Please let us know if we need to make more effort in improvement of this paper.

Yours sincerely,

Ping Xiao 


\section{Response to reviewers}

Reviewer \#2: Minor revisions

The paper was improved by the revisions and the responses were clear.

I would recommend few additional improvements:

\section{MINOR POINTS}

- Please check the following typos:

p. 3, "for the first, implements" -> "for the first time, implements"

p. 4: "was used to milled away" -> "was used to mill away"

p. 15: "with stress singularity is found at the crack tip" -> "with stress singularity at the crack tip"

Caption of Fig. 2: "(a) side view and (b) side view of" -> "(a) side view and (b) front view of" "(e) side view and (f) side view of" -> "(e) side view and (f) front view of"

Reply: These typos have been corrected.

\section{MAJOR POINTS}

- Some features in Fig. A2 are not clearly visible:

1) The $x, y, z$ labels in the bottom left triad of Fig. A2(a) are only readable when downloading and magnifying the original, high-resolution image. This will clearly not be possible in the printed paper version. I would therefore recommend to plot an enlarged triad. Reply: The Fig.A2(a) has been redrawn to improve the image quality and presentation. The triad is now clearly seen in the figure.

2) Likewise, the load application point on the cantilever is hardly visible at normal image size. Drawing a bigger arrow with an image editor would help identifying it.

Reply: The Fig.A2(a) has been redrawn to improve the image quality and presentation. The load point is now clearly seen in the figure.

3) The mentioned stress singularity at the crack tip is not clearly seen in panel (b).

Reply: The Fig.A2(b) has been redrawn to improve the image quality and presentation. The singularity at the crack tip is now zoomed in and can be clearly seen in the figure.

- Additional information on the FE model would be useful:

1) Section 2.4 mentions the use of cohesive zone modelling. This would imply either the use of a row of cohesive elements along the pre-defined crack propagation path, or of a crack propagation analysis based on defining cohesive behaviour in a surface-based contact model for the initially bonded crack faces. Some clarification is recommended, including details (e.g. a table) of input material parameters;

Reply: This is a misuse of the term "cohesive zone modelling". The text has now been changed to correct this mistake. The authors used extended finite element method (XFEM) to extract the shape factor. Stationery cracks of a series of lengths have been simulated and the stress intensity factor has been extracted for each crack length using the contour integral method. The use of XFEM avoids the need to conform the mesh to the crack geometry, making it easier for scripting. An isotropic linear elastic material with a Young's modulus of $120 \mathrm{GPa}$ and a Poisson's ratio of 0.2 has been used for the model. For each case, a dummy load of $1 \mathrm{~N}$ is applied and the average stress intensity factor $\mathrm{K}_{\mathrm{IC}}$ is calculated using 
the contour integral method in ABAQUS. Corresponding revisions have been made in Section 2.4 and Appendix A2.

2) Appendix A2 speaks of the "dimensionless shape factor [...] calculated from the FEA model". How was the shape factor extracted? For example, did the authors employ the contour integral evaluation method, implemented in ABAQUS, to extract KIC at the crack tip, and did they reverse eq. (4) to extract $\mathrm{f}(\mathrm{a} /(\mathrm{h} 1+\mathrm{h} 2))$ from KIC?

Reply: Yes. The contour integral integration method in ABAQUS has been used to calculate the average $K_{I C}$ at the crack tip for each crack length. The shape factor is then determined from Eqs. 4 and 5 by fitting the relation between crack length a and the $K_{\mathrm{IC}}$ as calculated by ABAQUS. This detail has been added into Section 2.4.

3) The new figure A2, which shows the finite element model mentioned above, contains some hardly readable elements (excessively small size).

Reply: Fig.A2 has been redrawn to improve the image quality and presentation. 
- Micro-cantilevers of an APS TBC were prepared and tested.

- The APS TBC is elastically anisotropic at microscale

- The in-plane and out-of-plane elastic modulus is $144 \mathrm{GPa}$ and $110 \mathrm{GPa}$, respectively.

- The fracture toughness parallel to the interface is $0.40 \mathrm{MPa} \sqrt{\mathrm{m}}$

- The fracture toughness depends on the measurement length scaleerack size. 


\title{
Measurements of Elastic Modulus and Fracture Toughness of an Air Plasma
}

\section{Sprayed Thermal Barrier Coating Using Micro-Cantilever Bending}

Ying Chen ${ }^{\mathrm{a}, 1}$, Xun Zhang ${ }^{\mathrm{a}, 2}$, Xiaofeng Zhao ${ }^{\mathrm{b}}$, Nicolaie Markocsan ${ }^{\mathrm{c}}$, Per Nylén $^{\mathrm{c}}$, Ping Xiao ${ }^{\mathrm{a},}$ $\mathrm{b \dagger}$

\author{
${ }^{a}$ School of Materials, University of Manchester, Manchester M13 9PL, UK \\ ${ }^{\mathrm{b}}$ Shanghai Key Laboratory of Advanced High-Temperature Materials and Precision Forming, \\ Shanghai Jiao Tong University, Shanghai, 200240, PR China \\ ${ }^{c}$ Department of Engineering Science, University West, Trollhättan, Sweden
}

\begin{abstract}
The elastic modulus and fracture toughness of an air plasma sprayed thermal barrier coating (APS TBC) were measured using the micro-cantilever bending technique. The microcantilevers were machined by a focused ion beam with their central arms either parallel or normal to the bond coat/topcoat interface. Such orientations allowed direct measurements of both the in-plane and out-of-plane elastic moduli as well as mode I fracture toughness by bending. The calculated elastic modulus along the in-plane and out-of-plane direction is $\sim 144$ GPa and $~ 110 \mathrm{GPa}$, respectively, suggesting that the APS TBC is elastically anisotropic at microscale. The derived mode I fracture toughness along the plane parallel to the interface is $\sim 0.40 \mathrm{MPa} \sqrt{\mathrm{m}}$. This relatively low toughness reflects the weak fracture resistance of the highly-flawed APS for short cracks at microscale. The measurements in this study can be incorporated into micromechanical life time prediction models of the APS TBCs.
\end{abstract}

Keywords: Elastic modulus; Fracture toughness; Micro-cantilever bending; Microstructure

\footnotetext{
$\dagger$ Corresponding author: Ping Xiao (p.xiao@manchester.ac.uk).

${ }^{1}$ Present address: OxMet Technologies, Begbroke Science Park, Oxfordshire, OX5 1PF, United Kingdom

${ }^{2}$ Present address: Department of Engineering Science, University of Oxford, Parks Road, Oxford, OX1 3PJ, UK
} 


\section{Introduction}

Air plasma sprayed thermal barrier coatings (APS TBCs) are widely used in gas-turbine engines to protect the thermally loaded components against hot gases and increase engine efficiency [1-3]. A typical APS TBC system consists of a refractory-oxide ceramic topcoat (typically made of 7-8 wt.\% yttria stabilised zirconia (YSZ)) and a MCrAlY (M=Ni,Co or $\mathrm{Ni} / \mathrm{Co}$ ) bond coat deposited on a superalloy substrate. APS TBCs undergo spallation failure of the ceramic topcoat after service at high temperature for a certain period of time. The failure of the TBCs is driven by the stress and associated strain energy stored in the ceramic layers induced by the thermal mismatch between the ceramic layers and substrate during cooling from the service temperature.

The architecture of a typical APS TBC is featured by a brick-wall structure with an assembly of horizontally-placed YSZ splats parallel to the coating surface and numerous inter/intrasplat cracks as well as scattered pores $[4,5]$. Due to this sheer complexity in microstructure, one of the greatest challenges for the APS TBCs is to have a comprehensive description and understanding of the material properties $[6,7]$, which are essential to understanding and predicting failure. It has been well established that failure of the APS TBCs mainly occurs at the base of the topcoat, through a sequence of crack nucleation, propagation and coalescence in planes parallel to the interface, driven by the local out-of-plane tensile stress and its associated strain energy around the undulated topcoat/bond coat interface [2, 8-10]. Prediction of crack growth in the vicinity of the undulations, therefore, requires detailed information of the elastic modulus and fracture toughness along the relevant direction over the characteristic length scale under the effect of the tensile stress. These arguments may be particularly important for the APS TBC showing anisotropic and size-dependent mechanical properties [2, $7,11]$. 
The main objective of this study is to characterise and understand the mechanical properties of an APS TBC at microscale using the micro-cantilever bending technique. The properties of interest are in-plane and out-of-plane modulus and mode I fracture toughness along the plane parallel to the interface, as they are tightly related to degradation and failure of the APS TBCs but have not yet been sufficiently characterised. The micro-cantilever bending method has been shown to be particularly useful in measurements of material anisotropy and mechanical properties of both bulk materials and coatings [12-15]. This technique creates simple and well-defined stress over the micro-cantilevers and, therefore, allowing the mechanical properties (e.g. elastic toughness and fracture toughness) along any direction to be readily

measured. This work, for the first time, implements this technique to measure the mechanical properties of the APS TBC at microscale. Following these measurements, we show how the measurements in this work could be fitted into the current micromechanical life time prediction models.

\section{Materials and Methods}

\subsection{Materials}

The material used in this study consists of a Hastelloy® X superalloy substrate $(55 \times 30 \times 5$ $\left.\mathrm{mm}^{3}\right)$, a NiCoCrAlY bond coat $(\sim 150 \mu \mathrm{m}$ thick $)$ and an $8 \mathrm{wt} . \%$ YSZ TBC $(\sim 250 \mu \mathrm{m}$ thick $)$. Both the YSZ TBC and NiCoCrAlY bond coat were deposited by APS. Details of the microstructure of the TBC have been reported elsewhere [16-19].

\subsection{Micro-cantilever preparation}

Micro-cantilevers were machined on polished surface and cross-section of the TBC using a focused ion beam (FIB, Quanta 3D DualBeam, FEI) following similar procedures described in the literature $[13,14]$. First, a large beam current of $7 \mathrm{nA}$ was used to mill two symmetric trenches $(5 \mu \mathrm{m}$ apart $)$ to create a rectangular central arm. The trenches were milled

sufficiently large and deep to ensure that the free end of the final micro-cantilever being 
bended would not contact either the side or bottom during bending. Next, the sample was tilted by $45^{\circ}$ around the long axis of the central arm and a beam current of $3 \mathrm{nA}$ was used to milled away the base of the central arm. The same process was repeated on the other side of the central arm after rotating the sample $180^{\circ}$ around its surface normal. The undercut removed the underlying material and produced a micro-cantilever with only one end attached to the surrounding material. Finally, both sides of the micro-cantilever were carefully polished with a current of $1 \mathrm{nA}$ to make them vertical and symmetric with respect to the central vertical axis.

The orientations of the micro-cantilevers are schematically illustrated in Fig.1. The microcantilevers machined on the surface allowed direct determination of the in-plane elastic modulus through bending. The micro-cantilevers on the cross-section were milled with such an orientation that their long axes of the central arms were paralleled to thermal spraying direction (normal to the bond coat/TBC interface). This orientation allows direct measurements of the out-of-plane elastic modulus and mode I fracture toughness through bending. Fig.2a-d show two typical micro-cantilevers milled on the TBC surface and cross-section, respectively. The cross-sections of the micro-cantilevers are pentagonal and symmetric with respect to their central vertical axes. The size of the micro-cantilever varies slightly from sample to sample, but typically with a length of $\sim 17-21 \mu \mathrm{m}$, width of $\sim 1.8-2.7$ $\mu \mathrm{m}$ and height of $\sim 2.8-3.4 \mu \mathrm{m}$. The length of the micro-cantilever on the cross-section generally spans over a few splats and inter-splat cracks, which are characteristic microstructural features of the APS coatings. In contrast, as the lateral diameter $(\sim 20 \mu \mathrm{m})$ of the splats is intrinsically larger than the thickness $(0.5-4 \mu \mathrm{m})$, the micro-cantilevers milled on the surface tend to have fewer cracks compared with those on the cross-section.

As the degradation and failure of the APS TBCs is generally manifested by cracking and delamination in the TBC parallel to the interface, the fracture toughness along the lateral 
trajectory is of most importance. Therefore, the micro-cantilevers milled on the cross-section of the TBC were used for fracture toughness measurement as the fracture planes of these micro-cantilevers would have the same orientation as those in the APS TBC during service. To measure fracture toughness using micro-cantilever bending, a sharp edge notch is generally introduced to simulate a real crack. However, as the horizontal inter-splat cracks almost spread all over the cross-section of the TBC, the micro-cantilever prepared on the cross-section most of the times ended up with an inter-splat crack near the fixed end. Under this circumstance, milling an edge notch would create extra stress concentration locations upon bending. This would introduce ambiguities in subsequent calculation. Therefore, to address this issue micro-cantilevers with well-delineated edge inter-splat cracks (e.g. Fig.2e and $\mathrm{f}$ where the edge crack is straight, reasonably deep and perpendicular to both top surface and sides of the micro-cantilever) near the fixed ends are used to determine the model I fracture toughness. Furthermore, the use of this real edge inter-splat crack also ensures that the crack tip is sharp enough, which is an important precondition to apply the solutions of linear fracture mechanics to calculate the fracture toughness.

Although the internal geometry of the edge inter-splat crack cannot be observed before bending, examination on the crack plane after rupture can easily reveal the original crack plane as it shows a completely different morphology with that generated during fracture. Specifically, the fracture of the TBC at room temperature is generally intergranular and the fracture plane revealed by bending is characterised by a high roughness compared with the original pre-existing crack plane. The inset in Fig.5 gives an example illustrating this difference. It is also seen that the pre-crack is approximately rectangular and the crack geometry will be used in calculation of fracture toughness. 


\subsection{Micro-cantilever bending}

Bending of the micro-cantilevers was conducted using a nanomechanical testing instrument (Hysitron PI SEM PicoIndenter) mounted inside the chamber of a scanning electron microscope (SEM, Zeiss Sigma). The SEM visualised the tests and provided live images to help pinpoint the indenter and contact point. A sapphire conical nanoindenter with a spherical tip of $\sim 2 \mu \mathrm{m}$ radius was used to apply the bending load. Unlike the indenters with sharp tips (e.g. Berkovich), the conical indenter with the spherical tip showed negligible impression into the micro-cantilever surface, which helped the load be fully transferred to bending force. The indenter tip was placed centrally across the width of the micro-cantilever, with the contact point approximately three quarters of the total length away from the fixed end. The bending was conducted with a rate of $2 \mathrm{~nm} / \mathrm{s}$ until the micro-cantilever snapped. The testing configuration and a full geometry description of the micro-cantilever are given in Fig.3.

\subsection{Determination of elastic modulus and fracture toughness}

The elastic modulus of the micro-cantilever, $E_{m}$, is calculated by:

$$
E_{m}=\frac{L_{P}^{3}}{3 I} \frac{d P}{d \delta}
$$

Where $L_{P}$ is the distance between the fixed end and the loading point. $P$ and $\delta$ is the load and the displacement at the loading point, respectively. $\frac{d P}{d \delta}$ is the gradient of the loaddisplacement curve and is obtained by fitting the curve with a linear function. For a pentagonal cross-section shown in Fig. 3, $I$ is given by (a detailed derivation of $I$ is given in Appendix A1):

$$
I=\frac{w h_{1}^{3}}{12}+\left(y-\frac{h_{1}}{2}\right)^{2} h_{1} w+\frac{w h_{2}^{3}}{36}+\left(\frac{h_{2}}{3}+h_{1}-y\right)^{2} \frac{w h_{2}}{2}
$$


Where $y$ is the vertical distance between the upper surface and the neutral plane, given by (a detailed derivation of $y$ is given in Appendix A1):

$$
y=\frac{6 h_{1}^{2}+3 h_{1} h_{2}+h_{2}^{2}}{12 h_{1}+3 h_{2}}
$$

The meanings of $w, h_{1}$, and $h_{2}$ are illustrated in Fig.3.

The mode I fracture toughness is calculated via the following equation [14]:

$$
K_{I C}=\sigma_{C} \sqrt{\pi a} F\left(\frac{a}{h_{1}+h_{2}}\right)
$$

where $\sigma_{C}$ is the fracture stress; $a$ is the crack length and $F\left(\frac{a}{h_{1}+h_{2}}\right)$ is a dimensionless shape factor dependent on the initial crack and beam geometry. $\sigma_{C}$ is given by:

$$
\sigma_{C}=\frac{P_{f} L_{C} y}{I}
$$

where $P_{f}$ is the load when the micro-cantilever fails and $L_{C}$ is the distance between the crack and the loading point.

The shape factor $F\left(\frac{a}{h_{1}+h_{2}}\right)$ is determined by finite element analysis (FEA) using cohesive zone modelling in ABAQUS 6.14 (see Appendix A2 for details). The beam and the attached matrix were first discretised using 3D elements (C3D8R) according to the geometry measured by SEM. Notches of different lengths were simulated as stationery cracks. The stress intensity factor at the notch tip induced by a dummy load of $1 \mathrm{~N}$ was evaluated using the contour integral method in ABAQUS. Three-dimensional elements were used to create the microeantilever beam and the attached matrix. The shape factors at different notch lengths were calculated by the model according to Eqs (4) and (5), and were then plotted against a series of 
the normalised crack lengths, $\frac{a}{h_{1}+h_{2}}$, within the range of $0.03 \leq \frac{a}{h_{1}+h_{2}} \leq 0.53$, and fitted using a $4^{\text {th }}$ order polynomial function, given by:

$$
\begin{aligned}
F\left(\frac{a}{h_{1}+h_{2}}\right)= & 1.57-3.39\left(\frac{a}{h_{1}+h_{2}}\right)+18.04\left(\frac{a}{h_{1}+h_{2}}\right)^{2} \\
& -35.5\left(\frac{a}{h_{1}+h_{2}}\right)^{3}+39.53\left(\frac{a}{h_{1}+h_{2}}\right)^{4}
\end{aligned}
$$

\section{Results and discussion}

\subsection{Elastic modulus}

Fig.4 shows the representative load-displacement curves obtained from bending of two microcantilevers. The micro-cantilevers were only used for elastic modulus measurements as they did not have well-delineated inter-splat cracks close to the support ends. It is seen that the micro-cantilevers show a linear load-displacement relationship before failure. Tables 1 and 2 give the geometry and calculated elastic moduli of the micro-cantilevers milled on the surface (5 in total) and cross-section (5 in total), respectively, based on linear fitting to the loaddisplacement curves $\left(R_{a d j}^{2}>0.99\right)$. The elastic modulus along the in-plane and out-of-plane direction is $144 \pm 12$ and $109 \pm 7 \mathrm{GPa}$, respectively. Both values are significantly higher than the global modulus (10-70 GPa) of the APS TBCs reported in the literature [11, 20-24]. The difference is expected as the characteristic volume of the material that undergoes deformation during micro-cantilever bending is only in the range of $\sim 60-110 \mu \mathrm{m}^{3}$, which is expected to contain far less defects than the macroscale TBC samples used for determination of the global modulus. On the other hand, it is found that the elastic modulus is anisotropic, with the inplane modulus $\sim 30 \%$ higher than the out-of-plane modulus, which is in agreement with the measurements by Wei. et al. [23]. The elastic anisotropy is believed to originate from the unique microstructure of the APS coating, which results in different types of characteristic microstructural defects and corresponding defect densities between the micro-cantilevers with 
different orientations. Specifically, the dominant microstructural defects in the micro-cantilevers on the TBC surface and cross-section are intra-splat and inter-splat cracks, respectively. As the lateral diameter of the splat is intrinsically much larger than the thickness, the number of the intra-splat cracks in the micro-cantilevers on the coating surface is smaller than the number of the inter-splat cracks in the micro-cantilevers on the coating cross-section, leading to a higher in-plane elastic modulus.

\subsection{Fracture toughness}

Fig.5 shows the load-displacement curve of a micro-cantilever with a well-delineated intersplat crack close to the support end. Micro-cantilevers with this feature were used for fracture toughness measurements. The curve is characterised by an initially linear portion, followed by a sequence of "pop-in" (the plateaus marked by the arrows in Fig.5) until failure. The "pop-in" is believed to result from crack propagation, which then leads to a sudden burst of the displacement.

Table 3 lists the fracture toughness calculated based on 5 micro-cantilevers and the corresponding geometry of each micro-cantilever. The fracture toughness is between 0.2 and $0.5 M P a \sqrt{m}$, with an average value of $0.40 \pm 0.12 M P a \sqrt{m}$. This value is significantly lower than the fracture toughness obtained from the same APS TBCs by Zhao et al using a modified four-point bending method (2-4MPa $\sqrt{m}$ [19]). The discrepancy is worth further discussion as it not only reflects the weak fracture resistance of the highly-flawed APS TBC at microscale, but also the dependence of the toughness on crack lengths. For the microcantilever bending tests conducted in this study, as the inter-splat cracks are used as the preexisting edge cracks for toughness measurements, the low mode I fracture toughness could be associated with crack propagation along the relatively weak splat interface. This crack path, however, is believed to represent the fracture of APS TBCs during service as previous literature have suggested that cracks prefer to propagate between the weakly bonded splats $[2$, 
$10,25]$. On the other hand, the toughness given by the micro-cantilever bending is the toughness for short cracks in the APS TBCs, which could be intrinsically lower than the toughness for long cracks (e.g. the cracks generated by four-point bending) [2, 7, 26, 27]. The difference is believed to be associated with the size-dependent mechanical behaviour of the APS TBC. At microscale, the APS TBCs show linear behaviour, as indicated by the linear load-displacement curves of the micro-cantilevers. However, non-linear behaviour and associated energy dissipation, such as anelastic stress-strain behaviour and hysteresis loaddisplacement loops, has been widely reported on macroscale TBC samples during deformation [28-30]. This anelastic behaviour and corresponding energy dissipation are likely to be involved when large-scale deformation and delamination in the APS TBC is generated (e.g. the delamination created by four-point bending) and contribute to the rise of the crack resistance (rise of the $\mathrm{R}$ curve).

\section{Correlation of measurements with micromechanical life time models of APS TBC}

The measurements of mechanical properties of the APS TBCs at microscale in this work also provide an opportunity to evaluate how these properties can be fit into the micromechanical life time prediction models of APS TBCs. The fundamental idea in most of the existing lifetime prediction models is that degradation of the APS TBCs is multiscale and progressive, with short cracks initially growing at microscale and then merging into large macroscale cracks to trigger failure. The implication here is that if the materials (e.g. APS TBCs) involved in the models have anisotropic and scale-dependent properties, this effect should be implemented to the models in order to have more accurate modelling and prediction.

To date, the micromechanical model proposed and developed by Vaßen et al is one of the most sophisticated attempts to mechanistically simulate failure of the APS TBCs during thermal cycling [25, 31-33]. The basic idea of the model is the growth of pre-existing micro- 
cracks in the APS TBCs close to the bond coat driven by the radial out-of-plane tensile stress in the vicinity of rough interface due to thermal mismatch stress between the TBC and the underlying metal upon cooling. The model involves simultaneous growth of numerous short cracks (with the crack length less than the wavelength of the interface profile) in the plane parallel to the interface and subsequent coalescence of the propagating cracks to reach sufficiently large cracks that finally trigger spallation of the TBC.

The governing equation describing the crack growth is given by[25]:

$$
\frac{\mathrm{d} a}{\mathrm{~d} N}=A\left(\frac{K_{I}}{K_{I, c}}\right)^{n}
$$

Where $a$ is crack length; $N$ is the number of thermal cycles; $\frac{\mathrm{d} a}{\mathrm{~d} N}$ is the crack growth rate per cycle; $A$ and $n$ are constants; $K_{I}$ is the stress intensity factor and $K_{I, C}$ is the critical stress intensity factor (mode I toughness) of the APS TBC. $K_{I}$ can be approximated by [25]:

$$
K_{I}=\sigma(l) \sqrt{\frac{\pi a}{2}}
$$

Where $\sigma(l)$ is the radial tensile stress given by [33] :

$$
\sigma(l)=E_{T B C}\left(\alpha_{B C}-\alpha_{T B C}\right)|\Delta T| \frac{A}{\lambda} \exp \left(-\frac{2 \pi}{\lambda} l\right) f\left(l, h_{T G O}\right)
$$

Where $l$ is the perpendicular distance from the interface; $\alpha$ is coefficient of thermal expansion; $E$ is elastic modulus; $\Delta T$ is the temperature drop during cooling; $A$ and $\lambda$ are amplitude and wavelength of the TBC/bond coat interface profile; $h_{T G O}$ is the thickness of the TGO; $f\left(l, h_{T G O}\right)$ is a function of $l$ and $h_{T G O}$. 
The factor $\exp \left(-\frac{2 \pi}{\lambda} l\right)$ in Eq (9) suggests that the radial tensile stress mainly concentrates in the $\mathrm{TBC}$ close to the interface and rapidly decreases with increasing distance away from the interface, which has also been confirmed by the finite element calculation [32]. For example, for a typical TBC/bond coat interface profile with an amplitude of $10 \mu \mathrm{m}$ and a wavelength of $65 \mu \mathrm{m}, \sigma$ virtually vanishes to 0 at a distance of $20 \mu \mathrm{m}$ away from the interface. This distance range is close to the characteristic lengths of the micro-cantilevers prepared in this study and therefore the out-of-plane elastic modulus determined by the micro-cantilever bending technique in this study is representative of $E_{T B C}$ and can be incorporated in the Eq (9). On the other hand, as the growth of cracks in this stage is microscale, $K_{I, c}$ in Eq (7) in principle represents the critical stress intensity factor for short crack. As a result, the Mode I fracture toughness determined from the micro-cantilever bending technique is representative of $K_{I, C}$ and therefore can be incorporated into $\mathrm{Eq}(7)$.

\section{Conclusions}

Micro-cantilevers of an APS TBC were prepared by FIB and the mechanical properties (elastic modulus and fracture toughness) of the APS TBC were measured by the microcantilever bending method. Micro-cantilever bending shows that the APS TBC is elastically anisotropic at microscale, with an in-plane and out-of-plane elastic modulus of $\sim 144 \mathrm{GPa}$ and $\sim 110 \mathrm{GPa}$, respectively. The elastic anisotropy is related to the different types of characteristic microstructural defects and corresponding defect densities between the microcantilevers with different orientations. The mode I fracture toughness along the lateral trajectory derived from micro-cantilever bending is $\sim 0.40 \mathrm{MPa} \sqrt{\mathrm{m}}$. This low toughness reflects the weak intrinsic fracture resistance of the highly-lawed APS TBC at microscale. The measurements of the mechanical properties in this study can be incorporated into micromechanical life time prediction models of the APS TBCs. 


\section{Acknowledgements}

The authors would also like to thank Mr. Andrew Forrest and Dr. Craig Williams for the help on micro-cantilever bending tests.

\section{Appendix A1: Derivation of the moment of inertia and neutral plane of a pentagonal cross-section}

Fig. A1 shows the geometry description of the pentagonal cross-section of the microcantilever. The pentagon can be broken down into a rectangle and an isosceles triangle, and the moment of inertia of the both segments with respect to the neutral axis could be derived using the parallel axis theorem [34].

The moment of inertia of the rectangle, $I_{R}$, with respect to its centroid axis is given by:

$$
I_{R}=\frac{w h_{1}^{3}}{12}
$$

As the distance from the centroid axis of the rectangle to the neutral axis is $y-\frac{h_{1}}{2}$, according the parallel axis theorem the moment of inertia of the rectangle, $I_{R}^{\prime}$, with respect to the neutral axis, is given by:

$$
I_{R}^{\prime}=\frac{w h_{1}^{3}}{12}+\left(y-\frac{h_{1}}{2}\right)^{2} w h_{1}
$$

The moment of inertial of the isosceles triangle, $I_{t}$, with respect to its centroid axis is given by:

$$
I_{t}=\frac{w h_{2}^{3}}{36}
$$


As the distance from the centroid axis of the isosceles triangle to the neutral axis is $\frac{h_{2}}{3}+h_{1}-$ $y$, according the parallel axis theorem the moment of inertia of the isosceles triangle, $I_{t}^{\prime}$, with respect to the neutral axis, is given by:

$$
I_{t}^{\prime}=\frac{w h_{2}^{3}}{36}+\left(\frac{h_{2}}{3}+h_{1}-y\right)^{2} \frac{w h_{2}}{2}
$$

By summing up contributions from both the rectangle (Eq (A2)) and isosceles triangle (Eq (A4)), we have the inertia of the pentagonal cross-section with respect to its neutral axis, which is given by $\mathrm{Eq}(2)$.

The position of the neutral plane relative to the upper surface, $y$, can be determined according to the force balance over the cross-section, expressed as:

$$
\underbrace{\int_{0}^{y} \frac{M x}{I} w d x}_{\text {Tension force }}-\underbrace{\left[\int_{0}^{h_{1}-y} \frac{M x}{I} w d x+\int_{h_{1}-y}^{h_{2}+h_{1}-y} \frac{M x}{I}\left(\frac{\frac{w}{2}\left(h_{2}+h_{1}-y-x\right)}{h_{2}}\right) d x\right]}_{\text {Compression force }}=0
$$

Where $M$ is the bending moment and $x$ is the distance from the element to be integrated to the neutral plane. Eq (A5) can be readily solved to obtain $y$, which is given by Eq (3).

\section{Appendix A2: Calculation of shape factor $f\left(\frac{a}{h_{1}+h_{2}}\right)$ by FEA}

The shape factor, $f\left(\frac{a}{h_{1}+h_{2}}\right)$, was determined by FEA using ABAQUS 6.14. Threedimensional elements (C3D8R) were used to ereate-discretise the cantilever beam and the matrix (Fig. A2a). The material was set to be pure elastic and isotropic with an homegeneous elastic modulus of $120 \mathrm{GPa}$ and a Poisson's ratio of 0.2 . An encastre boundary condition was set for the bottom of the matrix (xz plane in Fig.A2a). A point load of $1 \mathrm{~N}$ was created at the loading position as shown in Fig.A2a, which ramped up in the step of analysis. Due to the 
geometrical symmetry, only half of the micro-cantilever was modelled and a z-symmetry boundary condition was created for the symmetry plane (plane $z=0$ in Fig.A2a). The notch is modelled as a stationery crack using the extended finite element method (XFEM). This avoids the need to conform the mesh to the crack geometry, making it easier for scripting. The stress intensity factor at the notch tip was evaluated using the contour integral method in ABAQUS. A convergence study was performed and showed that 800000 elements were enough for the calculated contour integrals to converge. The geometry factor could be calculated using the dummy load (i.e. $1 \mathrm{~N}$ ) and the average stress intensity factor at the notch tip calculated by the contour integral.

A Python script was developed and implemented to calculate the shape factor as a function of the crack length. A model with an input eracknotch length was created and submitted for analysis. Once the analysis is completed, the script extracted the ealeulation results-average $\underline{\text { stress intensify factor at the notch tip from the output database. The geometry factor at this }}$ notch length was then calculated. The new crack length was then written into the result file and a This was followed by updating the model with the updated a new erack-notch length was generated-and the process repeated. Fig.A2b shows an example of the distribution of the stress in the beam axis direction. The beam is in tension in the top and compression at the bottom, with stress singularity is found at the crack tip. The dimensionless shape factor, $f\left(\frac{a}{h_{1}+h_{2}}\right)$, calculated from the FEA model is plotted against the normalised crack length, $\left(\frac{a}{h_{1}+h_{2}}\right)$, and fitted using a $4^{\text {th }}$ order polynomial function, as shown in Fig.A3. 


\section{References}

1. D.R. Clarke and C.G. Levi, Materials design for the next generation thermal barrier coatings. Annual Review of Materials Research, 2003. 33: p. 383-417.

2. A.G. Evans, D.R. Mumm, J.W. Hutchinson, G.H. Meier, and F.S. Pettit, Mechanisms controlling the durability of thermal barrier coatings. Progress in Materials Science, 2001. 46(5): p. 505-553.

3. N.P. Padture, M. Gell, and E.H. Jordan, Materials science - Thermal barrier coatings for gas-turbine engine applications. Science, 2002. 296(5566): p. 280-284.

4. R. Mcpherson, A Review of Microstructure and Properties of Plasma Sprayed Ceramic Coatings. Surface \& Coatings Technology, 1989. 39(1-3): p. 173-181.

5. S. Sampath, U. Schulz, M.O. Jarligo, and S. Kuroda, Processing science of advanced thermal-barrier systems. Mrs Bulletin, 2012. 37(10): p. 903-910.

6. D.R. Clarke, M. Oechsner, and N.P. Padture, Thermal-barrier coatings for more efficient gas-turbine engines. Mrs Bulletin, 2012. 37(10): p. 891-902.

7. R. Vassen, Y. Kagawa, R. Subramanian, P. Zombo, and D.M. Zhu, Testing and evaluation of thermalbarrier coatings. Mrs Bulletin, 2012. 37(10): p. 911-916.

8. P.K. Wright and A.G. Evans, Mechanisms governing the performance of thermal barrier coatings. Current Opinion in Solid State \& Materials Science, 1999. 4(3): p. 255-265.

9. K.W. Schlichting, N.P. Padture, E.H. Jordan, and M. Gell, Failure modes in plasma-sprayed thermal barrier coatings. Materials Science and Engineering: A, 2003. 342(1-2): p. 120-130.

10. A. Rabiei and A.G. Evans, Failure mechanisms associated with the thermally grown oxide in plasmasprayed thermal barrier coatings. Acta Materialia, 2000. 48(15): p. 3963-3976.

11. J.A. Thompson and T.W. Clyne, The effect of heat treatment on the stiffness of zirconia top coats in plasma-sprayed TBCs. Acta Materialia, 2001. 49(9): p. 1565-1575.

12. D.E.J. Armstrong, A.S.M.A. Haseeb, S.G. Roberts, A.J. Wilkinson, and K. Bade, Nanoindentation and micro-mechanical fracture toughness of electrodeposited nanocrystalline $N i$-W alloy films. Thin Solid Films, 2012. 520(13): p. 4369-4372.

13. D.E.J. Armstrong, A.J. Wilkinson, and S.G. Roberts, Measuring anisotropy in Young's modulus of copper using microcantilever testing. Journal of Materials Research, 2009. 24(11): p. 3268-3276.

14. D. Di Maio and S.G. Roberts, Measuring fracture toughness of coatings using focused-ion-beammachined microbeams. Journal of Materials Research, 2005. 20(2): p. 299-302.

15. D.E.J. Armstrong, C.D. Hardie, J.S.K.L. Gibson, A.J. Bushby, P.D. Edmondson, and S.G. Roberts, Small-scale characterisation of irradiated nuclear materials: Part II nanoindentation and microcantilever testing of ion irradiated nuclear materials. Journal of Nuclear Materials, 2015. 462: p. 374381.

16. C. Li, S.D.M. Jacques, Y. Chen, D. Daisenberger, P. Xiao, N. Markocsan, P. Nylen, and R.J. Cernik, A synchrotron $X$-ray diffraction deconvolution method for the measurement of residual stress in thermal barrier coatings as a function of depth. Journal of Applied Crystallography, 2016. 49: p. 1904-1911.

17. C. Li, S.D.M. Jacques, Y. Chen, P. Xiao, A.M. Beale, M. di Michiel, N. Markossan, P. Nylen, and R.J. Cernik, Precise strain profile measurement as a function of depth in thermal barrier coatings using high energy synchrotron X-rays. Scripta Materialia, 2016. 113: p. 122-126.

18. C. Li, X. Zhang, Y. Chen, J. Carr, S. Jacques, J. Behnsen, M. di Michiel, P. Xiao, and R. Cernik, Understanding the residual stress distribution through the thickness of atmosphere plasma sprayed (APS) thermal barrier coatings (TBCs) by high energy synchrotron XRD; digital image correlation (DIC) and image based modelling. Acta Materialia, 2017. 132: p. 1-12.

19. Y. Zhao, A. Shinmi, X. Zhao, P.J. Withers, S. Van Boxel, N. Markocsan, P. Nylen, and P. Xiao, Investigation of interfacial properties of atmospheric plasma sprayed thermal barrier coatings with four-point bending and computed tomography technique. Surface \& Coatings Technology, 2012. 206(23): p. 4922-4929.

20. S. Paul, Stiffness of Plasma Sprayed Thermal Barrier Coatings. Coatings, 2017. 7(5).

21. D. Schwingel, R. Taylor, T. Haubold, J. Wigren, and C. Gualco, Mechanical and thermophysical properties of thick PYSZ thermal barrier coatings: correlation with microstructure and spraying parameters. Surface \& Coatings Technology, 1998. 108(1-3): p. 99-106.

22. K. Ma, J. Zhu, H. Xie, and H. Wang, Effect of porous microstructure on the elastic modulus of plasmasprayed thermal barrier coatings: Experiment and numerical analysis. Surface and Coatings Technology, 2013. 235: p. 589-595.

23. Q. Wei, J. Zhu, and W. Chen, Anisotropic Mechanical Properties of Plasma-Sprayed Thermal Barrier Coatings at High Temperature Determined by Ultrasonic Method. Journal of Thermal Spray Technology, 2016. 25(3): p. 605-612. 
24. G. Li, H. Xie, G. Yang, G. Liu, C. Li, and C. Li, A comprehensive sintering mechanism for TBCs-Part I: An overall evolution with two-stage kinetics. Journal of the American Ceramic Society, 2017. 100(5): p. 2176-2189.

25. R. Vassen, G. Kerkhof, and D. Stover, Development of a micromechanical life prediction model for plasma sprayed thermal barrier coatings. Materials Science and Engineering: A, 2001. 303(1-2): p. 100-109.

26. P.F. Zhao, C.A. Sun, X.Y. Zhu, F.L. Shang, and C.J. Li, Fracture toughness measurements of plasmasprayed thermal barrier coatings using a modified four-point bending method. Surface and Coatings Technology, 2010. 204(24): p. 4066-4074.

27. Q. Zhu, W. He, J. Zhu, Y. Zhou, and L. Chen, Investigation on interfacial fracture toughness of plasma-sprayed TBCs using a three-point bending method. Surface and Coatings Technology, 2018. 353: p. 75-83.

28. S.R. Choi, High-temperature slow crack growth, fracture toughness and room-temperature deformation behavior of plasma-sprayed ZrO2-8 wt \% Y2O3. Ceramic Engineering and Science Proceedings, 1998. 19(4): p. 293-301.

29. S.R. Choi, D.M. Zhu, and R.A. Miller, Mechanical properties/database of plasma-sprayed ZrO2-8wt\% Y2O3 thermal barrier coatings. International Journal of Applied Ceramic Technology, 2004. 1(4): p. 330-342.

30. S.R. Choi, D.M. Zhu, and R.A. Miller, Effect of sintering on mechanical properties of plasma-sprayed zirconia-based thermal barrier coatings. Journal of the American Ceramic Society, 2005. 88(10): p. 2859-2867.

31. M. Ahrens, R. Vassen, and D. Stover, Stress distributions in plasma-sprayed thermal barrier coatings as a function of interface roughness and oxide scale thickness. Surface \& Coatings Technology, 2002. 161(1): p. 26-35.

32. F. Traeger, M. Ahrens, R. Vassen, and D. Stover, A life time model for ceramic thermal barrier coatings. Materials Science and Engineering: A, 2003. 358(1-2): p. 255-265.

33. R. Vassen, S. Giesen, and D. Stover, Lifetime of Plasma-Sprayed Thermal Barrier Coatings: Comparison of Numerical and Experimental Results. Journal of Thermal Spray Technology, 2009. 18(5-6): p. 835-845.

34. J.M. Gere, Mechanics of Materials, 6th Edition. Thomson Learning, Inc, 2004: p. p838. 
Fig.1 Schematic illustration of the orientations of the micro-cantilevers

Fig.2 Micro-cantilevers machined on the polished surface and cross-section of the APS TBC: (a) side view and (b) frontside view of a micro-cantilever milled on the surface for in-plane elastic modulus measurements; (c) side view and (d) front view of a micro-cantilever milled on the cross-section for out-of-plane elastic modulus measurements; (e) side view and (f) frontside view of a micro-cantilever for fracture toughness measurements.

Fig.3 Schematic description of the micro-cantilever geometry and the micro-cantilever bending test configuration

Fig.4 Typical load-displacement curves of the micro-cantilevers for elastic modulus measurements

Fig.5 Typical load-displacement curve of the micro-cantilever for fracture toughness measurements. The insets show that the micro-cantilever fractures along the pre-existing inter-splat crack near the fixed end and the fracture plane revealed by bending is characterised by a high roughness compared with the original pre-existing crack plane

Fig.A1 Geometry description of the pentagonal cross-section of the micro-cantilever

Fig.A2 Calculation of the shape factor using FEA: (a) 3D FE models for stress intensity factor calculation and (b) an example of stress contour in the beam axis (x-axis) for a beam with $\frac{a}{h_{1}+h_{2}}=0.43$

Fig.A3 Shape factor as a function of $\frac{a}{h_{1}+h_{2}}$ and corresponding numerical fitting 
Table.1 Elastic modulus of the micro-cantilevers on the surface (in-plane direction) and corresponding geometry

\begin{tabular}{lcccccc}
\hline & $\boldsymbol{w}(\boldsymbol{\mu m})$ & $\boldsymbol{h}_{\boldsymbol{1}}(\boldsymbol{\mu m})$ & $\boldsymbol{h}_{\mathbf{2}}(\boldsymbol{\mu m})$ & $\boldsymbol{L}_{\boldsymbol{P}}(\boldsymbol{\mu m})$ & $\boldsymbol{L}(\boldsymbol{\mu m})$ & $\boldsymbol{E}(\boldsymbol{G P a})$ \\
\hline Micro-cantilever 1 & 2.56 & 1.65 & 1.69 & 16.32 & 21.7 & 141.18 \\
Micro-cantilever 2 & 1.83 & 1.77 & 1.11 & 13.75 & 18.33 & 130.23 \\
Micro-cantilever 3 & 2.11 & 1.67 & 1.29 & 12.97 & 17.29 & 160.36 \\
Micro-cantilever 4 & 2.13 & 1.52 & 1.31 & 13.49 & 17.99 & 136.15 \\
Micro-cantilever 5 & 2.26 & 1.73 & 1.35 & 15.26 & 20.34 & 152.67 \\
\hline
\end{tabular}


Table.2 Elastic modulus of the micro-cantilevers perpendicular to the interface (out-of-plane direction) and corresponding geometry

\begin{tabular}{ccccccc}
\hline & $\boldsymbol{w}(\boldsymbol{\mu m})$ & $\boldsymbol{h}_{\boldsymbol{1}}(\boldsymbol{\mu m})$ & $\boldsymbol{h}_{\mathbf{2}}(\boldsymbol{\mu m})$ & $\boldsymbol{L}_{\boldsymbol{P}}(\boldsymbol{\mu m})$ & $\boldsymbol{L}(\boldsymbol{\mu m})$ & $\boldsymbol{E}(\boldsymbol{G P a})$ \\
\hline Micro-cantilever 6 & 1.99 & 1.68 & 1.18 & 13.17 & 17.56 & 112.88 \\
Micro-cantilever 7 & 2.01 & 1.80 & 1.08 & 13.59 & 18.12 & 118.22 \\
Micro-cantilever 8 & 2.65 & 1.64 & 1.83 & 16.17 & 21.56 & 101.93 \\
Micro-cantilever 9 & 2.53 & 1.62 & 1.67 & 14.0625 & 18.75 & 103.47 \\
Micro-cantilever 10 & 2.37 & 1.53 & 1.26 & 13.0875 & 17.45 & 113.03 \\
\hline
\end{tabular}


Table.3 Fracture toughness of the micro-cantilevers and corresponding geometry

\begin{tabular}{lcccccccc}
\hline & $\boldsymbol{w}(\boldsymbol{\mu m})$ & $\boldsymbol{h}_{\boldsymbol{1}}(\boldsymbol{\mu m})$ & $\boldsymbol{h}_{\mathbf{2}}(\boldsymbol{\mu m})$ & $\boldsymbol{L}_{\boldsymbol{P}}(\boldsymbol{\mu m})$ & $\boldsymbol{L}_{\boldsymbol{c}}(\boldsymbol{\mu m})$ & $\boldsymbol{L}(\boldsymbol{\mu m})$ & $\frac{\boldsymbol{a}}{\boldsymbol{h}_{\mathbf{1}}+\boldsymbol{h}_{\mathbf{2}}}$ & $\boldsymbol{k}_{\boldsymbol{I C}}(\boldsymbol{M P a} \sqrt{\boldsymbol{m}})$ \\
\hline Micro-cantilever 11 & 1.91 & 1.84 & 1.2 & 13.59 & 9.63 & 18.12 & 0.14 & 0.21 \\
Micro-cantilever 12 & 2.25 & 1.48 & 1.41 & 15.44 & 12.31 & 20.58 & 0.23 & 0.49 \\
Micro-cantilever 13 & 2.12 & 1.52 & 1.23 & 12.97 & 10.61 & 17.29 & 0.22 & 0.4 \\
Micro-cantilever 14 & 2.08 & 1.75 & 1.16 & 13.89 & 10.39 & 18.53 & 0.18 & 0.35 \\
Micro-cantilever 15 & 1.98 & 1.69 & 1.29 & 14.88 & 11.38 & 19.84 & 0.25 & 0.51 \\
\hline
\end{tabular}




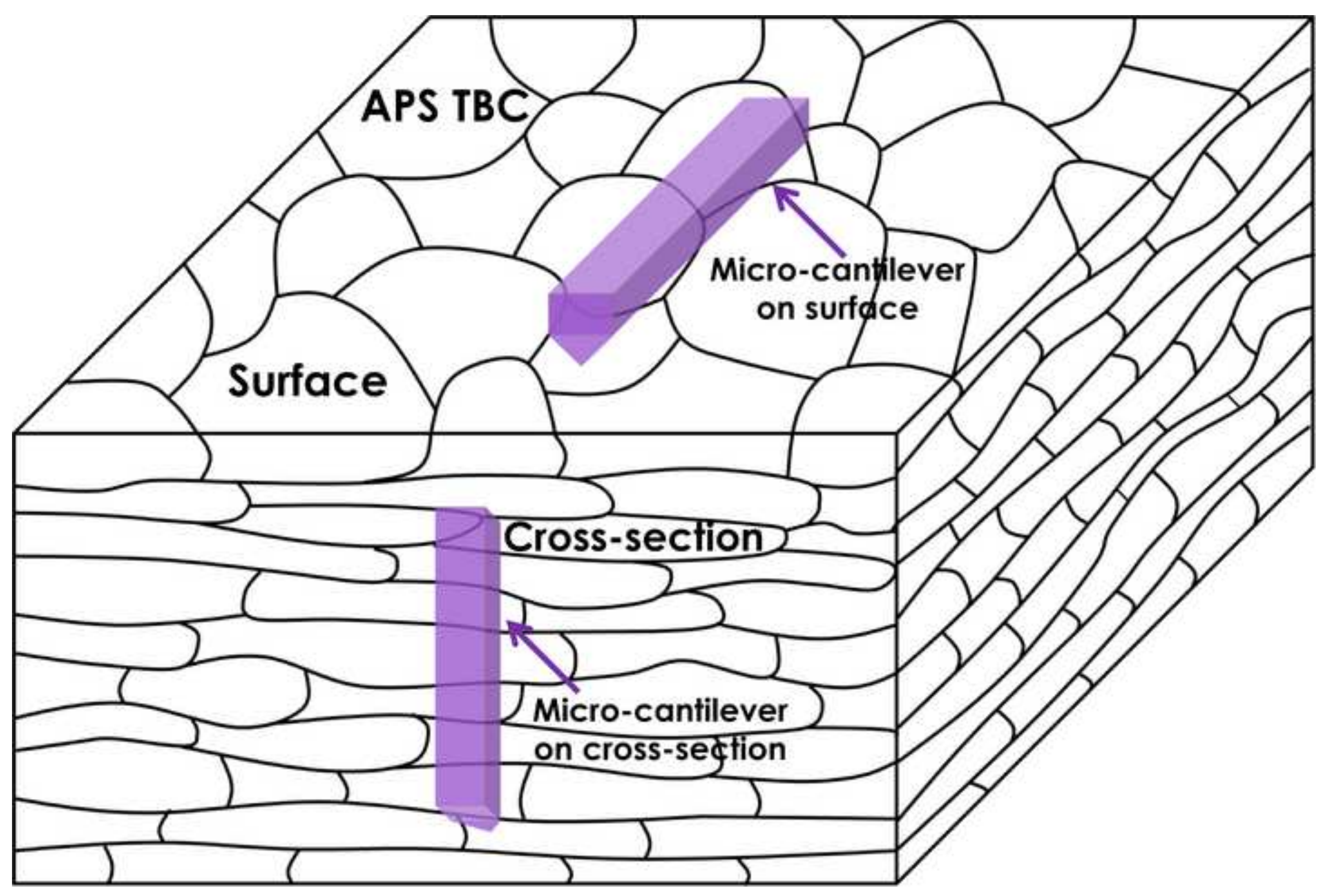


Click here to download high resolution image

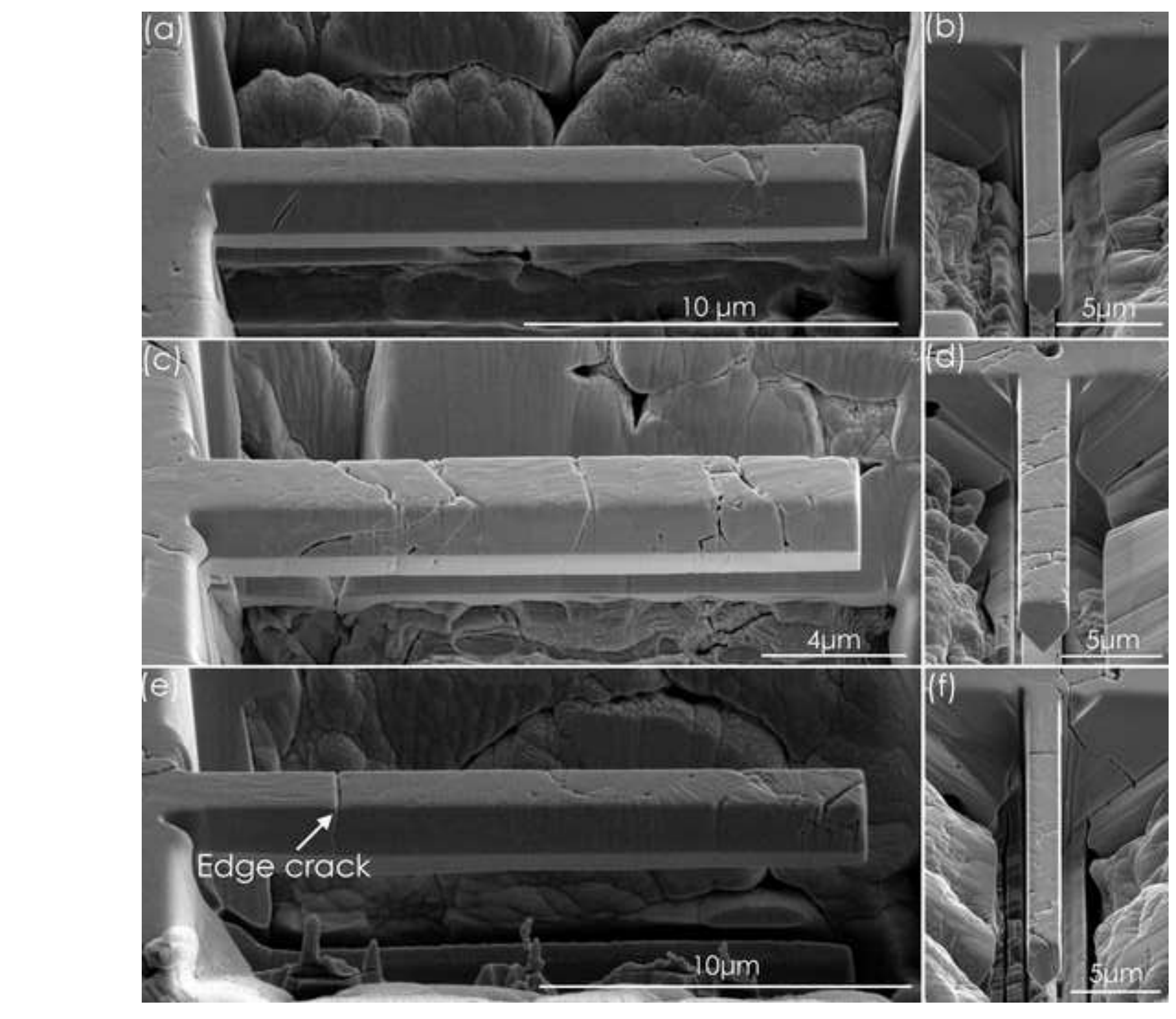




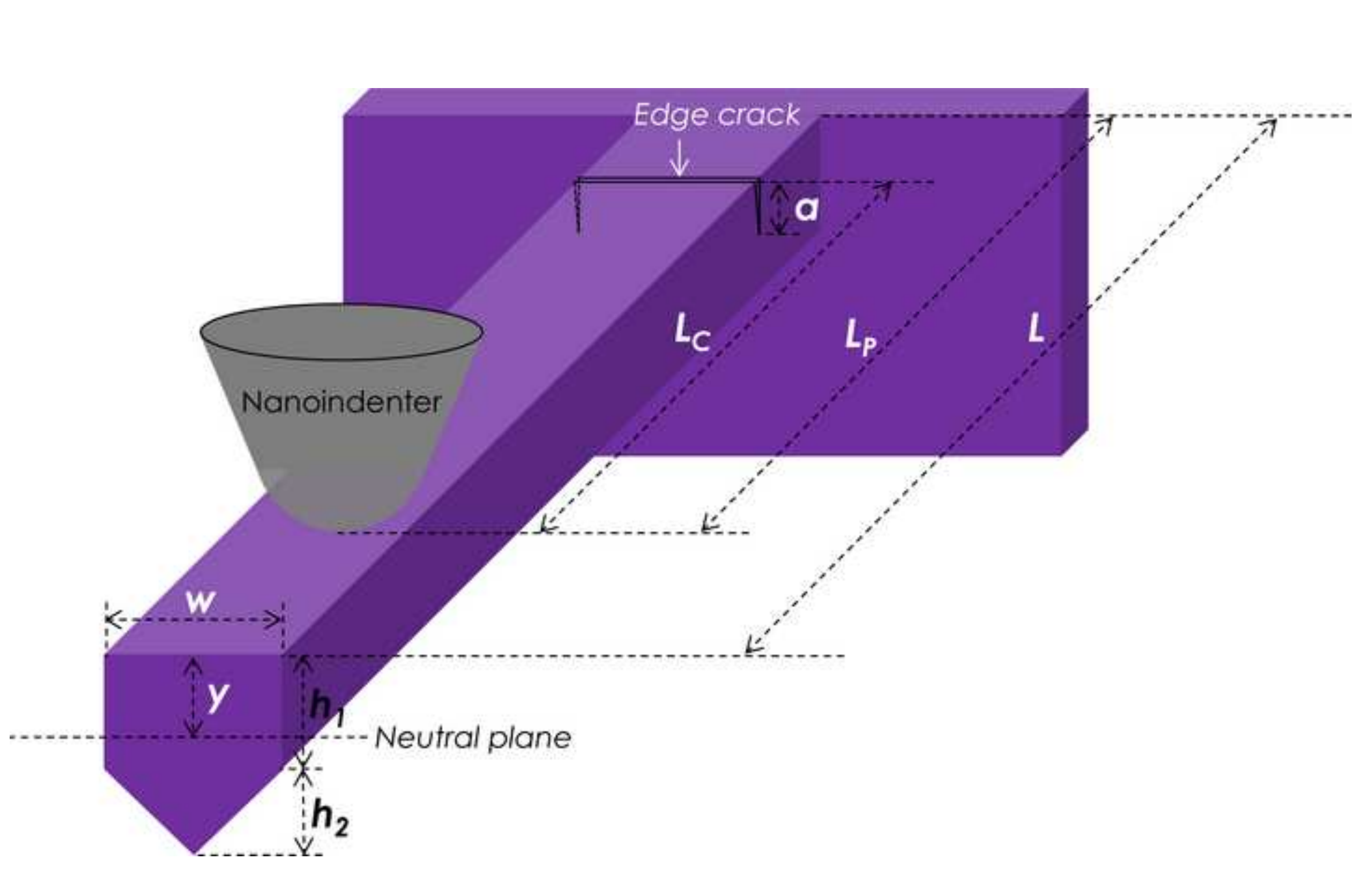

Clck here to download high 


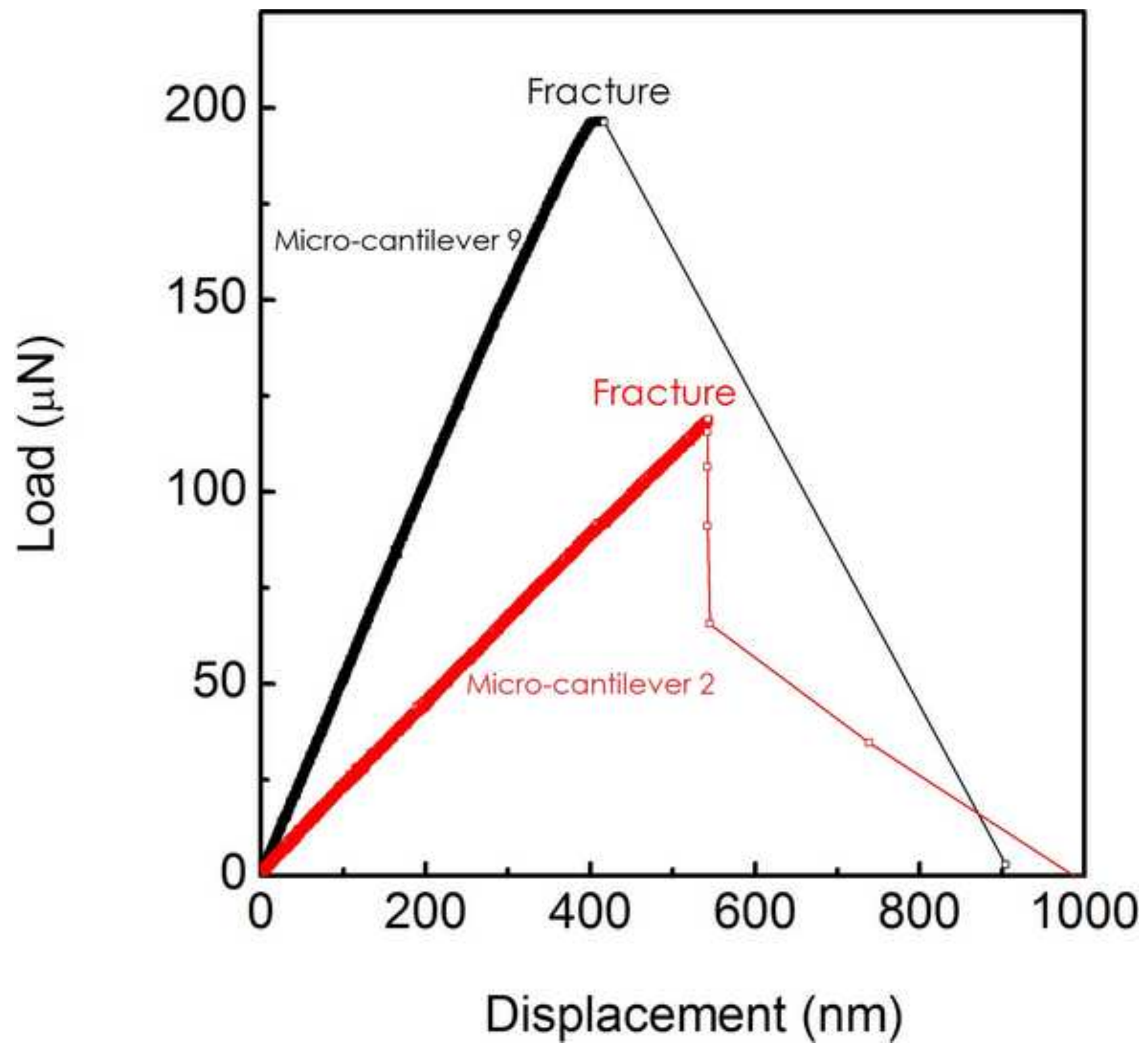




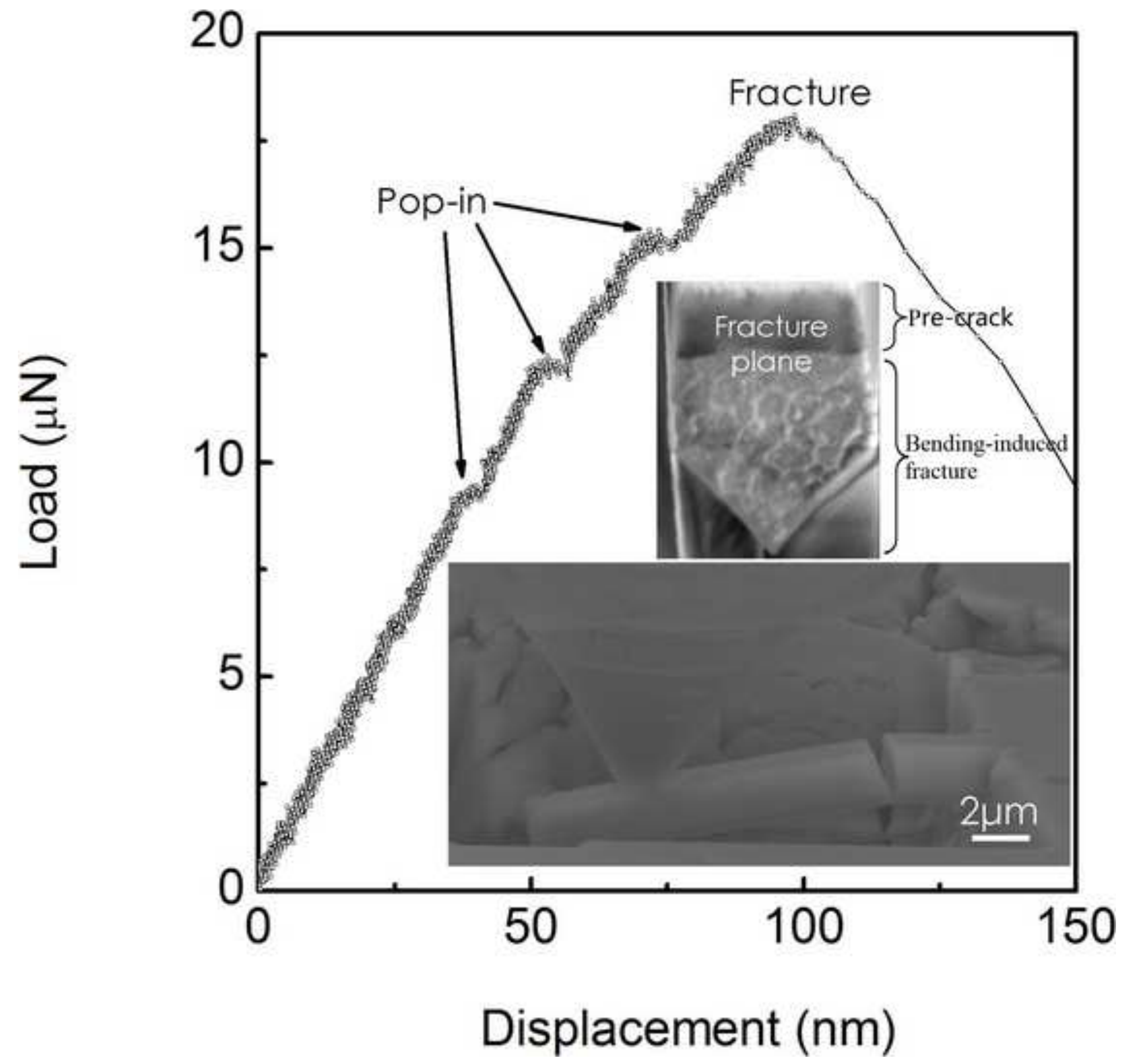




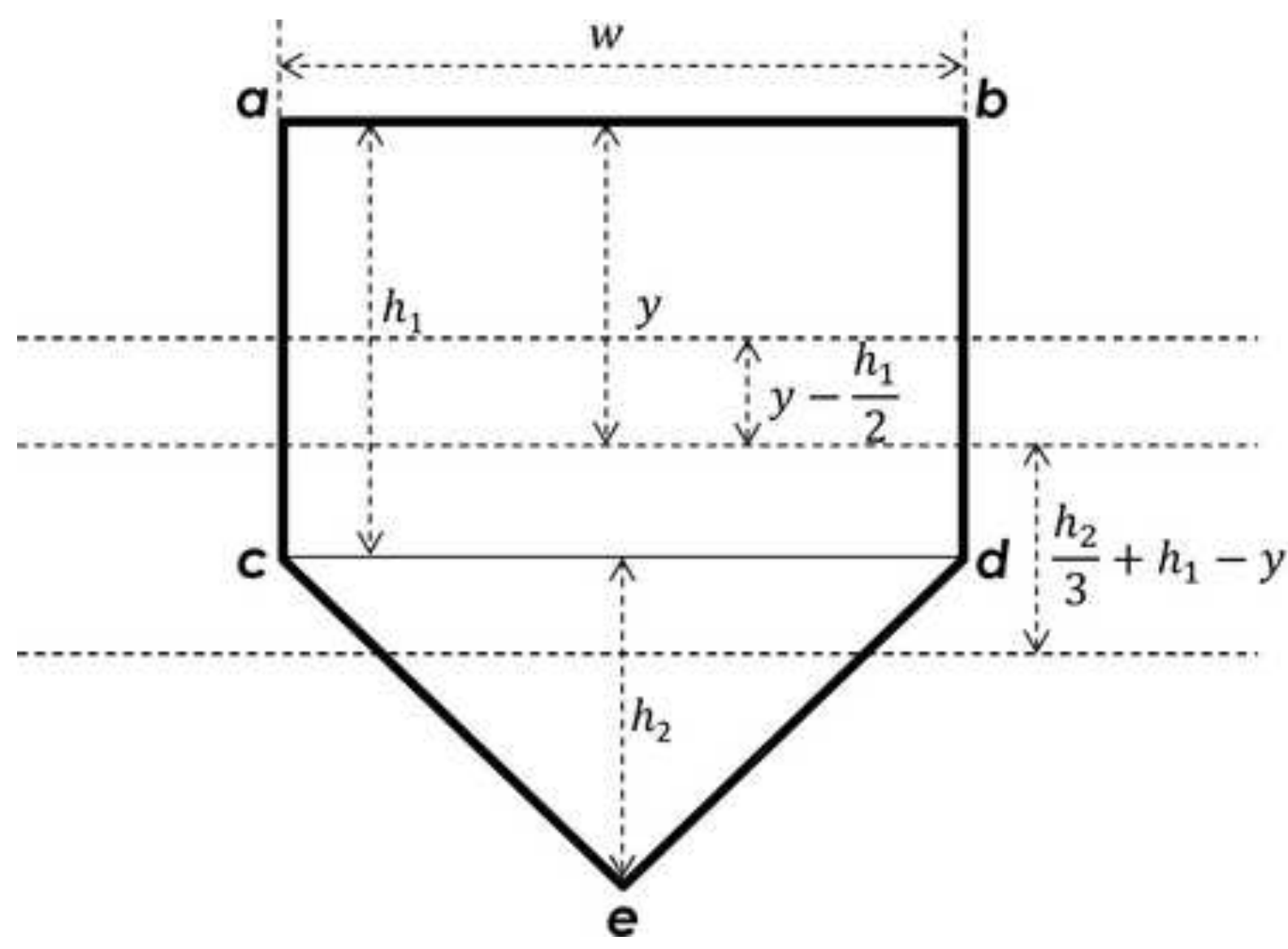

Centroid axis of rectangle abcd

Neutral axis of pentagon abcde

Centroid axis of isosceles triangle cde 
Click here to download high resolution image

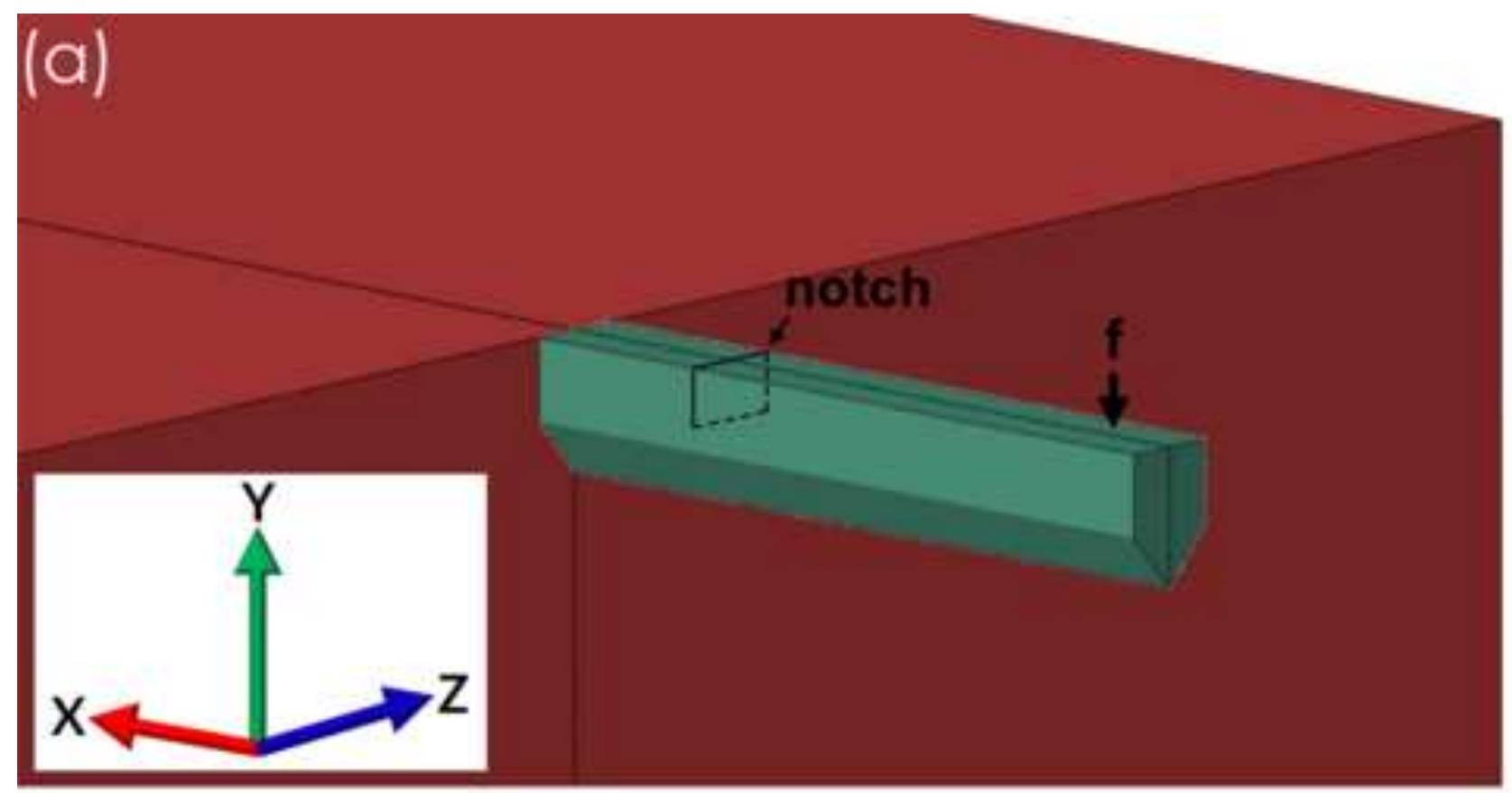

(b)

S, S11

(Avg: 75\%)
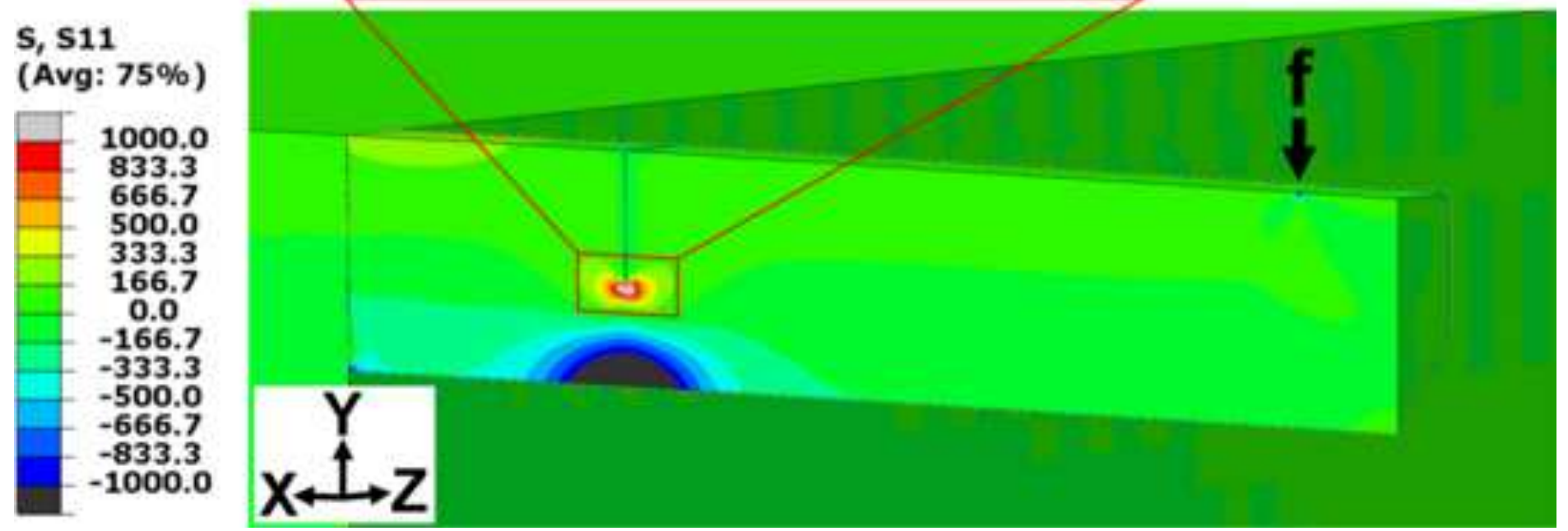


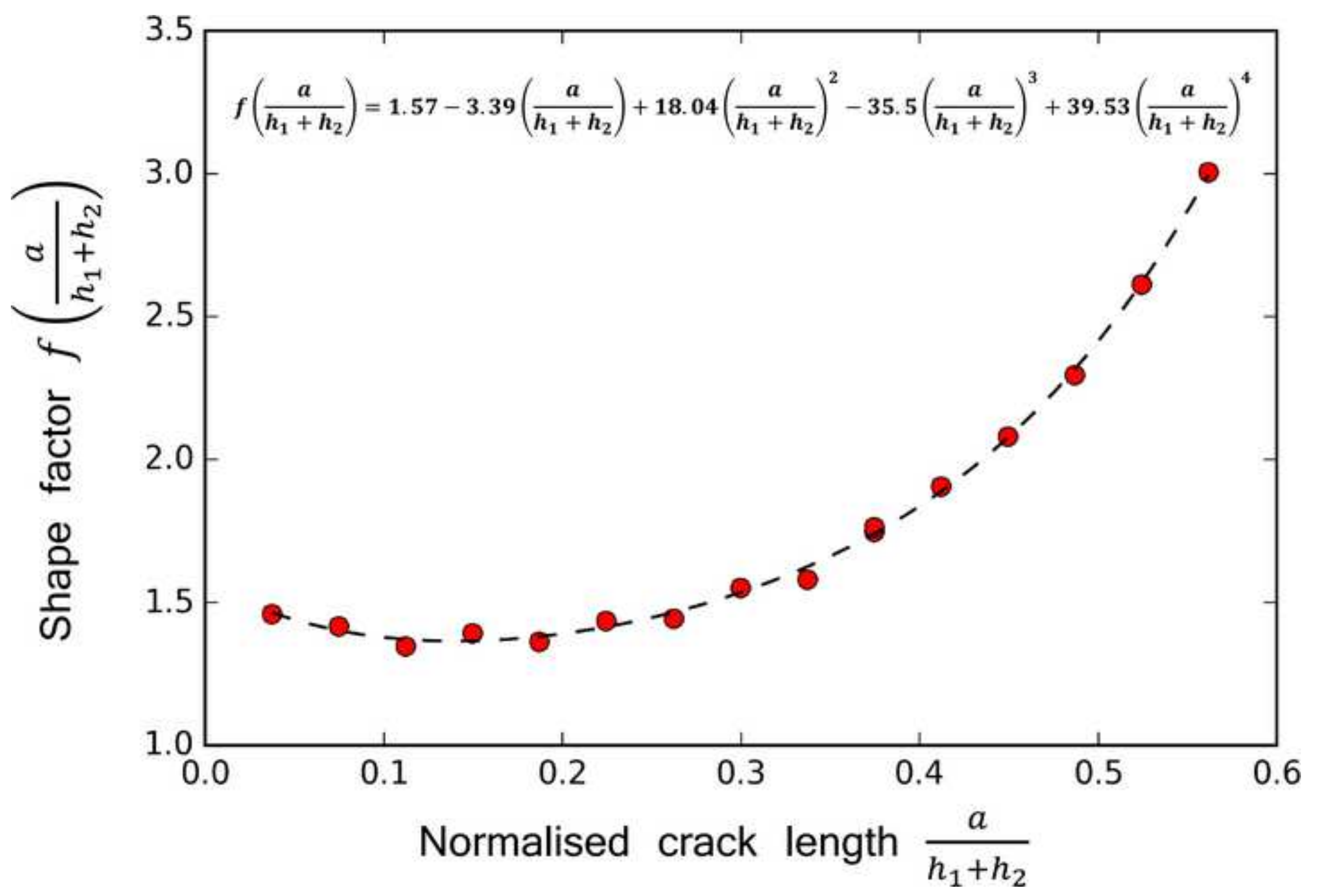



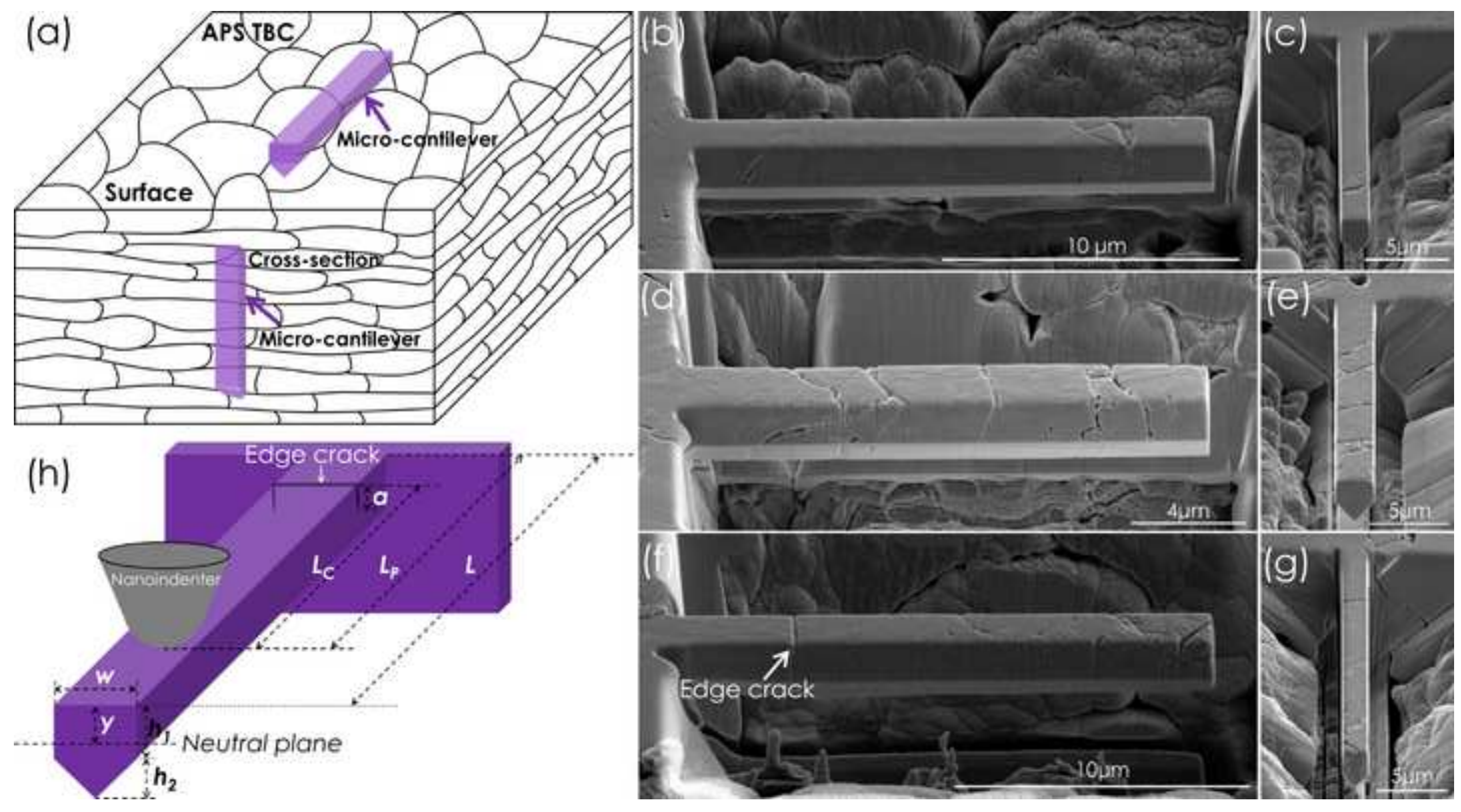